\title{
Evolución tipológica de cubiertas ventiladas 'a la catalana' en la obra de Antonio Bonet
}

\section{Typological evolution of 'catalan' ventilated roofs in the work of Antonio Bonet}

\author{
J. F. Ródenas García ${ }^{(*)}$
}

\section{RESUMEN}

En este trabajo analizamos la evolución de una serie de edificios diseñados por Antonio Bonet que comparten una tipología constructiva de origen vernáculo: la cubierta ventilada 'a la catalana'. Trataremos de demostrar el método investigador de Bonet quien no concibe la forma en sus proyectos como una pura invención personal. El patrón puede mutar o transgredirse por diferentes motivos, ya sea para adaptarse al avance tecnológico de un sistema constructivo, ya sea por adaptaciones topográficas, climáticas o programáticas.

A partir de la información del archivo del arquitecto, elaboramos y presentamos nueva documentación gráfica, a través del redibujado de las obras, con el objetivo de ordenar un material de archivo de difícil acceso por diferentes motivos: dispersión, diferencia de escalas, diferentes soportes gráficos. Con este trabajo, cualquier interesado puede obtener los datos básicos de cada edificio.

Palabras clave: Antonio Bonet; albañilería; bóvedas tabicadas; cerámica armada; arquitectura vernácula.

\section{ABSTRACT}

In this study we analyse the evolution of a series of buildings designed by Antonio Bonet that share the same vernacular construction typology: the 'Catalan' ventilated roofs. We try to demonstrate the investigatory method of Bonet, who does not regard form in his projects as a purely personal invention. The pattern may mutate or transgress for different reasons, whether to adapt to the technological advances of a building system or to programmatic, topographic or climatic changes.

On the basis of the information in the architect's archive, we create and present new graphical documentation through the redrawing of his works in order to organise archive material that is difficult to access due its dispersal, different scales and different formats. The present study will enable anyone interested to obtain basic data on each building.

Keywords: Antonio Bonet; masonry; tile vaults; reinforced brick construction; vernacular architecture.

(*) Universitat Rovira i Virgili.

Persona de contacto/Corresponding author: juanfernando.rodenas@urv.cat (J. F. Ródenas García)

ORCID: http://orcid.org/oooo-0001-8661-9901 (J. F. Ródenas García)

Cómo citar este artículo/Citation: Ródenas García, J. F. (2018). Evolución tipológica de cubiertas ventiladas 'a la catalana' en la obra de Antonio Bonet. Informes de la Construcción, 70(549): e245. https://doi.org/10.3989/ic.16014

Copyright: (C) 2018 CSIC. Este es un artículo de acceso abierto distribuido bajo los términos de la licencia de uso y distribución Creative Commons Reconocimiento 4.0 Internacional (CC BY 4.0). 


\section{INTRODUCCIÓN. SERIES BONETIANAS}

Uno de los aspectos que caracterizan a Bonet como proyectista radica en el método de trabajo, ya que no trata de resolver el encargo como una cuestión de estilo, su investigación va más allá, en una búsqueda de tipos o patrones, como elementos susceptibles de ser mejorados, perfeccionados y sistematizados. Como trataremos de demostrar, el patrón puede mutar o transgredirse por diferentes motivos, ya sea para adaptarse al avance tecnológico de un sistema constructivo, ya sea por adaptaciones topográficas, climáticas o programáticas tal y como ejemplifican las grandes arquitecturas del pasado. Bonet expresó los fundamentos teóricos sobre la idea de patrón en arquitectura en el VII CIAM, Bérgamo (1949) en los párrafos conclusivos de su ponencia: «Nuevas precisiones sobre arquitectura y urbanismo»(1):

\section{...Los elementos arquitectónicos que formarán la nueva ciudad estarán formados por una serie, poco numero- sa, de estructuras sistematizadas. Estas estructuras po- drán llegar al máximo de su perfección estética, técnica y económica, ya que además de estar colocadas en te- rrenos libres, su estudio estará basado en el perfeccio- namiento de los mismos tipos tal como se ha hecho con las grandes arquitecturas del pasado.}

Bonet renuncia a la repetición exacta, como trataremos de demostrar, cada nueva propuesta, aunque derive de experiencias anteriores, siempre incorpora mejoras del sistema ligadas íntimamente a las condiciones del programa o del lugar. El encadenamiento de experiencias con sus aciertos y sus errores confieren un poso que valida la propuesta tal y como sucede, tanto en las grandes arquitecturas del pasado, como en las «arquitecturas sin arquitecto» de la tradición vernácula. La riqueza de matices de su obra impide cualquier tipo de aproximación generalista, en cualquier caso, en una primera aproximación, sus obras de arquitectura se pueden agrupar en tres series que vamos a denominar como series Bonetianas. Dichas series se expresan con lenguajes diferenciados, aunque, en ocasiones se muestre un lenguaje híbrido, caracterizado por mestizajes tipológicos. La serie triangular/hexagonal se caracteriza por la definición de las plantas según una malla a $120^{\circ}$. Bonet y Josep Puig Torné, ensayan diferentes implantaciones en Salou (Tarragona) utilizando esquemas triangulares que dan forma a pabellones, plataformas y patios (2), valga de ejemplo: la casa Rubio, (1959). Por otra parte, Bonet aprovecha el potencial del hexágono para generar recintos a escala urbana (3). El hexágono puede formarse por segmentos rectos articulados por cajas de escalera, como sucede en las viviendas del poblado Hifrensa (1967-75), otra estrategia consiste en que el propio edificio forma un hexágono que se multiplica por repetición enlazado por uno de sus lados, como sucede en el conjunto hexagonal (1963). Por otra parte, identificamos experiencias tendentes a la abstracción, que el propio autor define como obras de carácter neoplástico (4), caracterizada por el uso de estructuras metálicas que forman mallas modulares tridimensionales con sistema de cubrición plano. Alguna de las obras que pertenecen a esta serie son: el Pabellón Cristalplano (1960) y la Casa Oks (1955-57), de la etapa española, cabe destacar el anteproyecto de la Casa Benito Perojo (1963). Bonet emplea en esta serie el lenguaje racionalista reconocible de los años cincuenta.

Sin embargo, Bonet trata de evitar la solución de techos planos en sus obras de un modo obsesivo, tema que nos permite introducir la serie más utilizada por Bonet: la serie de expresión escultórica de la cubierta, en la que Bonet utiliza un lenguaje que parte de la interpretación del sistema constructivo tradicional de cubiertas ventiladas 'a la catalana', normalmente resueltas con bóvedas tabicadas, utilizando entramados modulares de extensión horizontal. La hipótesis de este artículo muestra la evolución tipológica de la serie resuelta con cubiertas tabicadas. Debe apuntarse que la mayoría de trabajos académicos que ofrecen análisis constructivos referidos a la obra de Bonet $(5)(6)(7)(8)$ (9)(10)(11) restringen la mirada al uso de bóvedas. En este artículo trataremos de completar la serie incluyendo soluciones resueltas con cubiertas troncocónicas, piramidales y esféricas.

\section{BÓVEDAS, CÚPULAS Y PIRÁMIDES. INFLUENCIA VERNÁCULA}

[sic] Otro elemento que he usado mucho para conseguir mis finalidades ha sido los diferentes tipos de bóvedas... que uso para crear esos espacios interiores escultóricos y ámbitos de carácter humano...es decir, entiendo que el círculo envuelve mejor al ser humano que el rectángulo...es evidente que el rectángulo no tiene nada que ver con el ser humano...nosotros no tenemos ningún ángulo recto ni agudo no?...Este problema de la bóveda ha sido una constante en mi. Últimamente he hecho una casa que la considero una de las más importantes...en que incorporo la bóveda pero convertida en cúpula...son unas cúpulas casi semiesféricas que crean más todavía este recogimiento del ser humano con sus colegas...es evidente que bajo un elemento de estos se siente uno mas arropado que en un elemento paralelepípedo normal. Otro elemento que yo he usado para conseguir este carácter de recogimiento humano es la pirámide...como Ud. está viendo aquí como en la casa en la manga del mar menor en que todos los elementos modulares son pirámides...revestidos con una cerámica popular muy especial. (12).

Bonet muestra atención, tanto a la resolución escultórica de las cubiertas, como a la creación de espacios interiores cualificados ya desde su ingreso en Jeanneret Architectes. 35 Rue de Sèvres, donde colabora, entre 1936 y 1937, con Roberto Matta en los anteproyectos para la Maison Jaoul y el Pabellón del Agua para la Exposición Internacional de Lieja. Es conocido (13)(14) que ambos proyectos se caracterizan por el contraste entre la fuerza expresiva de la cubierta y el orden de la retícula de pilotis que reflejan las plantas, alejándose de la tradición lingüística del estilo internacional. Le Corbusier, ya, en 1919 había explorado la seriación con bóvedas en el proyecto no realizado de las casas Monol (1919). El descubrimiento de la técnica catalana se remonta a 1928, cuando Le Corbusier viaja a Barcelona, invitado por Josep Lluís Sert para pronunciar una conferencia sobre los cinco puntos de la nueva arquitectura (15). Le Corbusier apunta en sus cuadernos, dibujos acotados de las bóvedas que observa en las escuelas de la Sagrada familia de Gaudí (16). Elementos como la bóveda que posteriormente utilizarán Bonet, Sert y el propio Le Corbusier, asesorado por Domènec Escorsa (17), en algunos proyectos como la versión que finalmente se construyó de La Maison Jaoul, París, en 1954-56 (18) dibujada por Bonet para el mismo cliente en la versión de 1937. Escorsa, maestro de obras catalán, colaboró con Sert y Luís Lacasa en el Pabellón de la República Española para la Exposición 
Internacional de París (1937). Por su parte, Bonet colaboró con Sert y Torres Clavé con tan solo 19 años, en el proyecto de las casetas de fin de semana del Garraf, Sitges (1932-35). Las casetas se publicaron (19) en el número 19 de la revista AC, Documentos de Actividad Contemporánea y representan las inquietudes del GATEPAC por la tradición vernácula. No resulta extraño observar en las fotografías de éstas arquitecturas incipientes: cestos, vasijas, sillas y alfombras confeccionadas con tejidos de fibras naturales, objetos populares de uso doméstico, sin pretensiones artísticas que están validados por el poso del tiempo y acaban convirtiéndose en 'standard'. En el número anterior, 18, de la revista AC, dedicado a la arquitectura popular, Sert reivindicaba las raíces mediterráneas de la arquitectura moderna (20). La arquitectura popular, sin estilo, contiene, en esencia, las aspiraciones de los primeros arquitectos modernos: ausencia de ornamento, adecuación al uso y el sentido unitario que procura la sistematización de las soluciones constructivas con escasez de recursos. Las obras que vamos a analizar, se entienden a partir de éstos parámetros. Bonet conocía la seriación con bóvedas rebajadas ya en 1935, al colaborar con Sert y Torres Clavé en el parvulario de Viladecans, Barcelona (21). Ya en solitario, utilizará el sistema por primera vez en el concurso para el laboratorio de aeronáutica de la UNLP, junto a Hilario Zalba, en 1944. En el laboratorio, la articulación de dos volúmenes distintos a partir de un puente (22) separando dos áreas funcionales, anticipa la solución adoptada posteriormente en la casa Berlingieri (1947).

A continuación se expone el análisis de una selección de obras que forman la serie caracterizada por la expresión de la cubierta. Por cuestión de acotación metodológica, se ofrece una síntesis. Se prescinde de aquellas obras que por repetición o similitud no aportan conceptos nuevos, como el conjunto de casas en Martínez (1942); las versiones no realizadas del poblado Hifrensa (1967) o la Casa Mur, Barcelona (1945). También se prescinde de aquellas obras resueltas de un solo trazo aunque presenten cubrición escultórica, tal es el caso de los edificios auxiliares de la central nuclear de Vandellòs-I (1967). Se propone un cuadro comparativo (Fig. 1) para facilitar la lectura del análisis.

\section{PUNTO DE PARTIDA. CASA BERLINGIERI, 1947}

La casa Berlingieri (Fig. 2) supone el primer eslabón de la serie. El sistema de cubrición se basa en la técnica tradicional de cubierta ventilada 'a la catalana' cuyo origen se remonta a la construcción del terrat (azotea) en la Barcelona del siglo XIX (23). La construcción del terrat se sistematiza debido al aumento demográfico que supone la industrialización de la ciudad a partir de finales del siglo XVIII. El terrat estaba formado por dos forjados, el forjado inferior, era horizontal y estaba formado inicialmente por vigas de madera. $\mathrm{Al}$ principio, el forjado exterior se formaba con pendientes hacia el interior del edificio, y posteriormente con salida de aguas por el exterior de la fachada. El forjado superior, a diferencia del anterior, estaba formado por una solera cerámica de tres roscas de rasilla apoyado en la parte superior de las viguetas de madera y 'atacado' perimetralmente (24) con minvells: bateaguas (Fig. 3). A finales del siglo XIX se sustituyen las vigas de madera del forjado inferior por vigas de hierro y en el forjado superior se mantiene la solera cerámica aunque se sustituyen las vigas de madera por tabiquillos conejeros. La ventilación se producía por orificios situados en la fachada y en los patios interiores, creando así una circulación de aire que desecaba cualquier filtración (25). La separación entre la capa soportante y la capa exterior permite desvincular al edificio de las dilataciones y contracciones producidas por la exposición directa a la intemperie. En el periodo comprendido entre 1930 y 1937, los arquitectos del GATCPAC partieron del esquema de cubierta ventilada 'a la catalana' en sus proyectos (26), incorporando 'nuevos materiales': planchas aglomeradas de corcho, 'hormigón-esponja' y aglomerados de cemento-viruta. También se ensayaron soluciones con nuevos productos hidrófugos y asfálticos que proporcionaba la industria química: telas 'tectinadas' Callendrite y Durax. Por tanto, Bonet debió conocer el detalle de los edificios donde se aplicó el sistema, como es el caso del edificio de la calle Muntaner (Barcelona) Josep Lluís Sert (1931), entre otros.

Si observamos la sección constructiva de la Casa Berlingieri (Fig. 3) podemos identificar con claridad cada componente del sistema constructivo: el canal oculto de recogida de pluviales; la gárgola que se formaliza con una teja árabe empotrada en la fachada; la cámara de aire formada por tabiquillos; el soporte, en este caso de cerámica armada, y el remate superior, formado por un revestimiento de baldosín cerámico. Bonet utiliza por primera vez las técnicas de cerámica armada, asesorado por Eladio Dieste. Sobre una cimbra móvil (27)(28) con la forma de la catenaria, se coloca el soporte estructural, formado por una hoja de ladrillo puesto de plano, con juntas de $2 \mathrm{~cm}$, colocadas con mortero que incorporan 2 armaduras de $4 \mathrm{~mm}$, colocadas cada $25 \mathrm{~cm}$. La bóveda mayor se construye del mismo modo, aunque se aumenta el tamaño de la juntas $(3 \mathrm{~cm})$, se aumenta el diámetro de las armaduras $(6 \mathrm{~mm})$, y se refuerza una armadura en sentido opuesto, rematando la bóveda superiormente con un enlucido de mortero de $1 \mathrm{~cm}$. Las bóvedas descansan sobre una estructura de muros de carga, en consecuencia, el empuje horizontal se contrarresta por unos tirantes metálicos anclados a un zuncho perimetral que recorre lateralmente cada bóveda. La cámara de aire se forma con el mismo ladrillo puesto de canto a modo de tabique conejero. La capa superior descansa sobre los tabiques y está formada por una rosca de ladrillo común rematada superiormente por baldosas cerámicas que cumplen la función de impermeabilización. El esquema estructural coincide con el esquema de la cubierta y con el esquema programático formando un sistema. La planta se resuelve desdoblando en dos los ejes NO-SE de la estructura generándose un ritmo definido por un módulo intermedio, «A» y las bóvedas rebajadas, «B» de los dormitorios y la bóveda, algo mayor, que define la sala. El módulo intermedio, de menor altura $(2.10 \mathrm{~m})$ contiene la canal de recogida de pluviales y los espacios de servicio, también vestidores y baños de los dormitorios. El sistema lleva implícito la capacidad aditiva y distributiva y se caracteriza por la íntima relación entre contenido constructivo y expresión formal.

\section{CASA LA RICARDA, 1949-62}

Bonet retoma el uso de la bóveda rebajada, aumentando considerablemente el tamaño del módulo que pasa de 6.05m (Berlingieri) a 8,80m (La Ricarda) (29). En esta ocasión, Bonet prescinde de una estructura muraria. Aquí las jácenas que sostienen la bóvedas descansan sobre esbeltos perfiles metálicos 2 LPN-120 y el empuje lateral se contrarresta con tirantes de acero formados por perfiles UPN-100 que a su vez forman un dintel en los tramos acristalados (30). Se perfecciona el sistema de cubrición aligerando el 


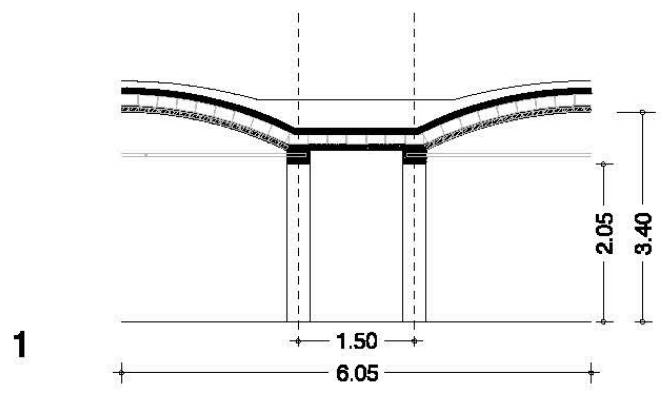

\section{5}
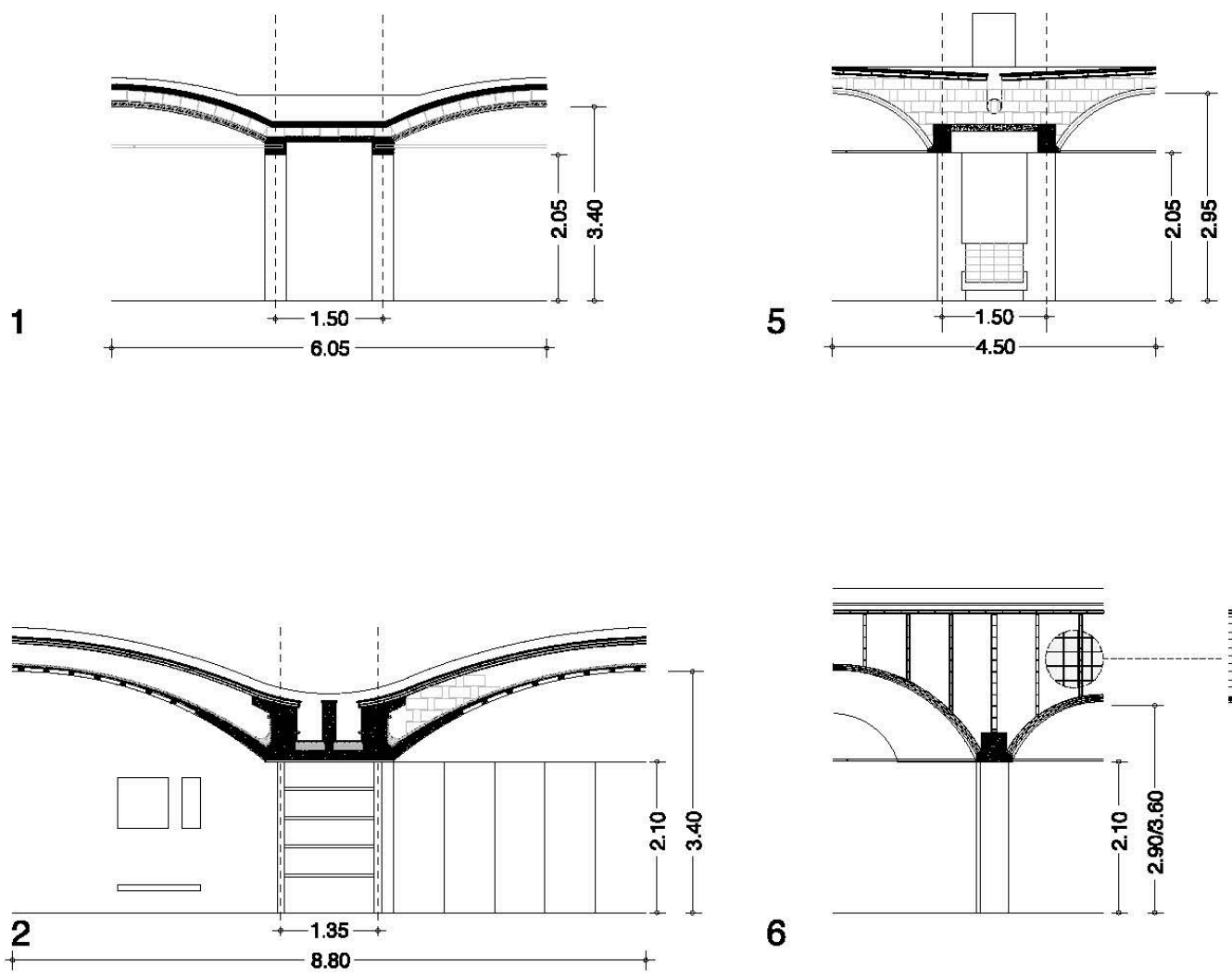

6

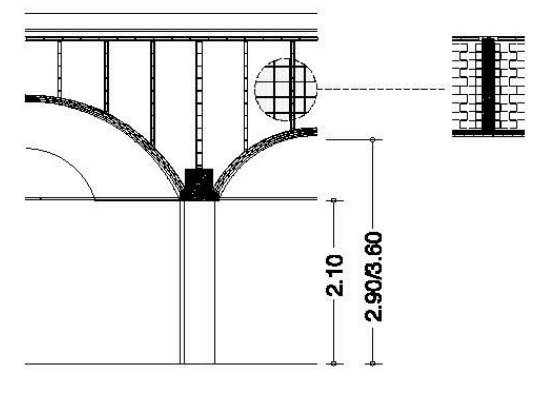

3
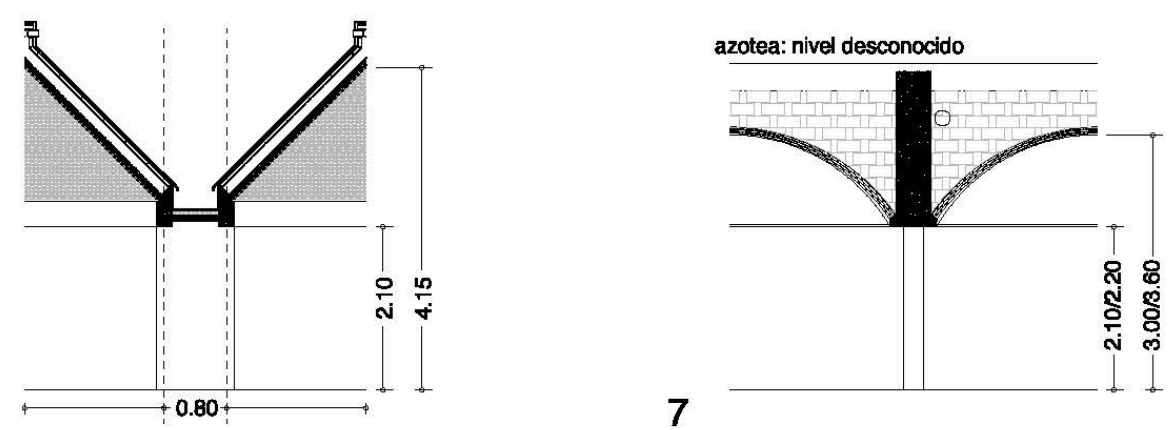

4
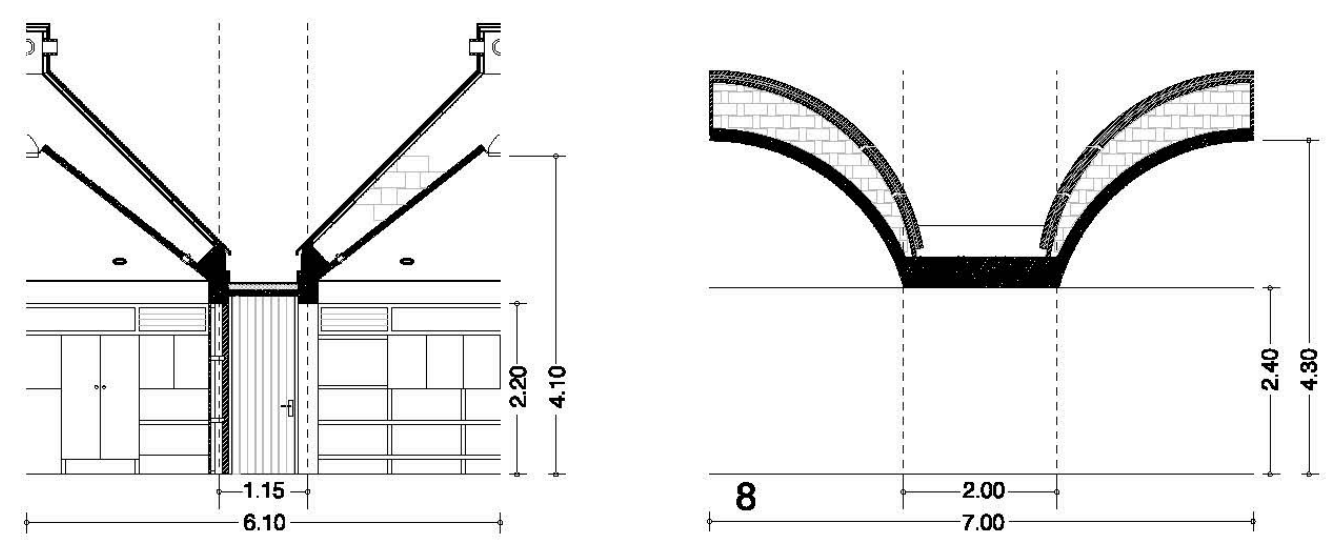

Figura 1. Cuadro comparativo: 1. Casa Berlingieri (1947); 2. Casa La Ricarda (1949-62); 3. Casa Rubio (1966); 4. Escuela del poblado Hifrensa (1967-75); 5. Viviendas y Bungalós (Bordas)(1968); 6. Bungalós Atamaría (1972); 7. Casa Raventós (1973-74); 8. Casa Balañà, (1974). 


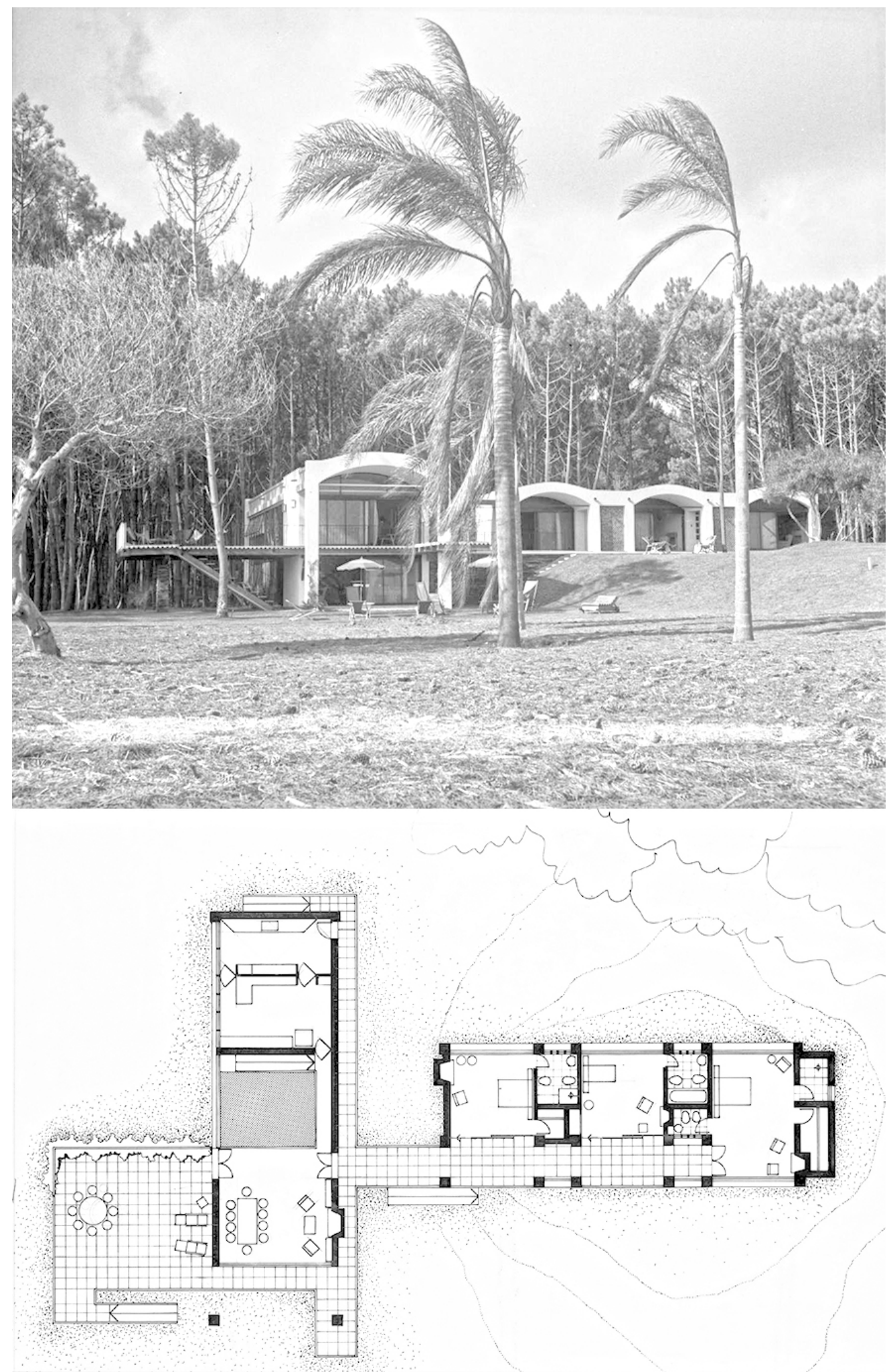

Figura 2. Casa Berlingieri. Fuente: AHC

soporte estructural de hormigón de la bóveda con piezas cerámicas a petición del constructor Emilio Bofill, quien escribe al arquitecto, sugiriéndole «insertar ladrillos huecos entre los nervios de la bóveda de hormigón armado para conseguir aliviar el peso de ésta» (31). La trama estructural se resuelve del mismo modo que la casa Berlingieri, es decir, desdoblando, en este caso, los ejes N-S de la estructura, generando un ritmo definido por un módulo intermedio, «A» $\mathrm{y}$ las bóvedas, «B» con la particularidad de que las bóvedas se diseñan con unas cavidades interiores que definen un doble canalón que revela la posibilidad de 'deslizar' entre sí cada bóveda, consiguiendo libertad de movimientos en planta y permitiendo intercalar patios y delimitar áreas exteriores con celosías ordenadas según el orden dictado por la trama. Sobre el soporte estructural, se apoyan los tabiquillos formando una cavidad ventilada mediante tubos de fibroce- 


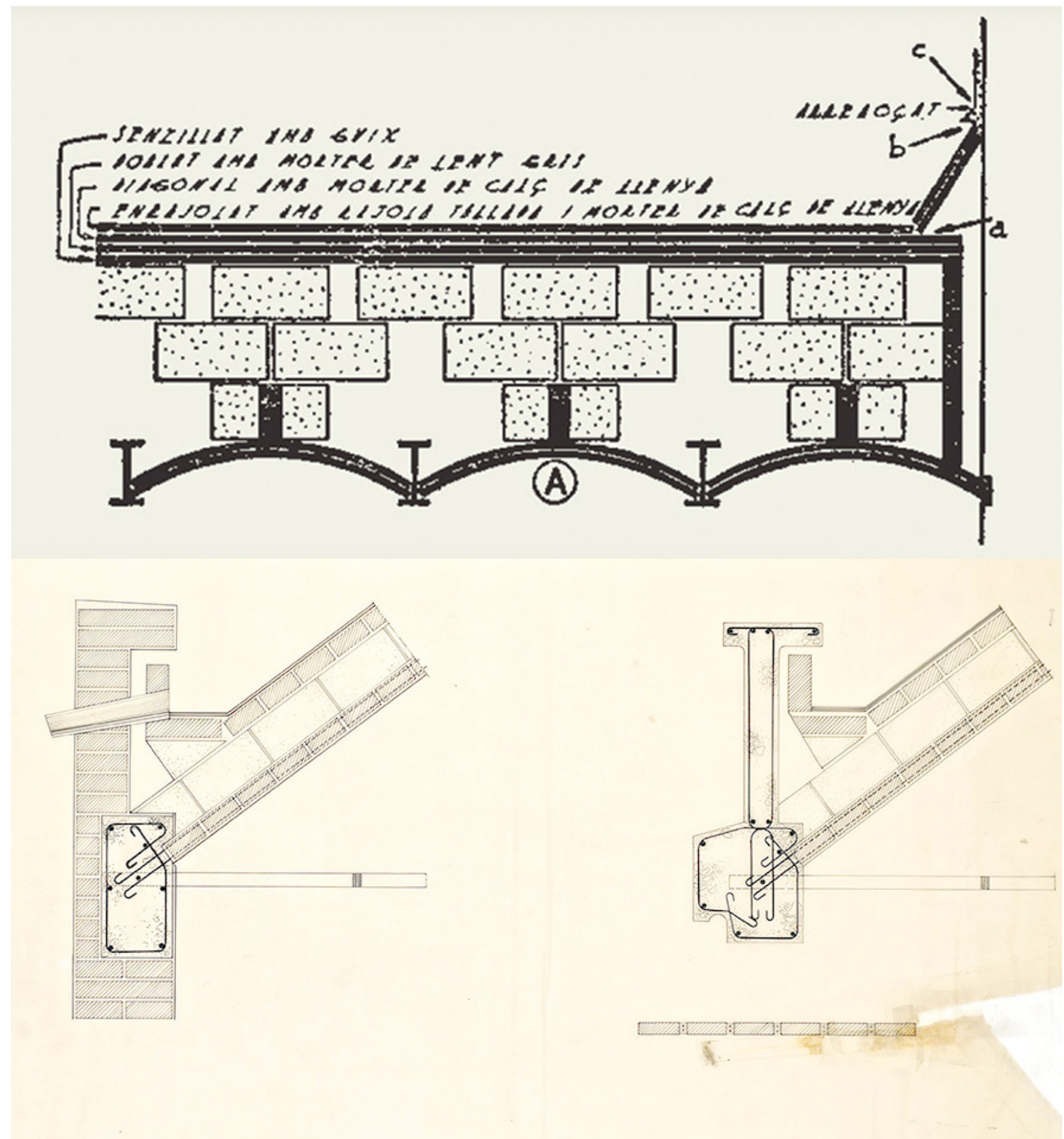

Figura 3. Azotea catalana según Benavent (24) / casa Berlingieri. Fuente: AHC.

mento que respiran hacia los canalones ocultos atravesando lateralmente las jácenas. La capa final está formada por un tablero doble de rasilla cruzada rematada superiormente por una tela asfáltica protegida con baldosín de gres salado de la casa Cucurny (32). Mientras que la casa Berlingieri presenta un desarrollo lineal, en la casa La Ricarda, como en el juego de ajedrez, sobre un damero virtual, el módulo se puede desplazar en dos direcciones (Fig. 4). En este sentido, debe apuntarse el sistema propuesto por Louis I. Kahn en la Casa de Vore, Montgomery County, USA, (1954-55). Kahn propone un elemento modular, con una estructura autónoma, capaz de repetirse según reglas precisas (33).

\section{CASA RUBIO, 1966}

Bonet ensaya con módulos piramidales (Fig. 5) en otra vivienda unifamiliar de gran superficie: la Casa Rubio. Con fuertes condicionantes climáticos ya que la casa se sitúa en La Manga del mar menor, una estrecha franja de tierra que queda entre dos mares. En esta ocasión, Bonet mantiene la estructura modular bidireccional que ya conocemos, aunque disminuye el tamaño del módulo justo a la mitad: 8.80m (La Ricarda) y 4.40m (Rubio). La pirámide provoca en el interior de la casa una sensación de espacio 'central', de mayor recogimiento respecto a la sensación de espacio 'direccional' 


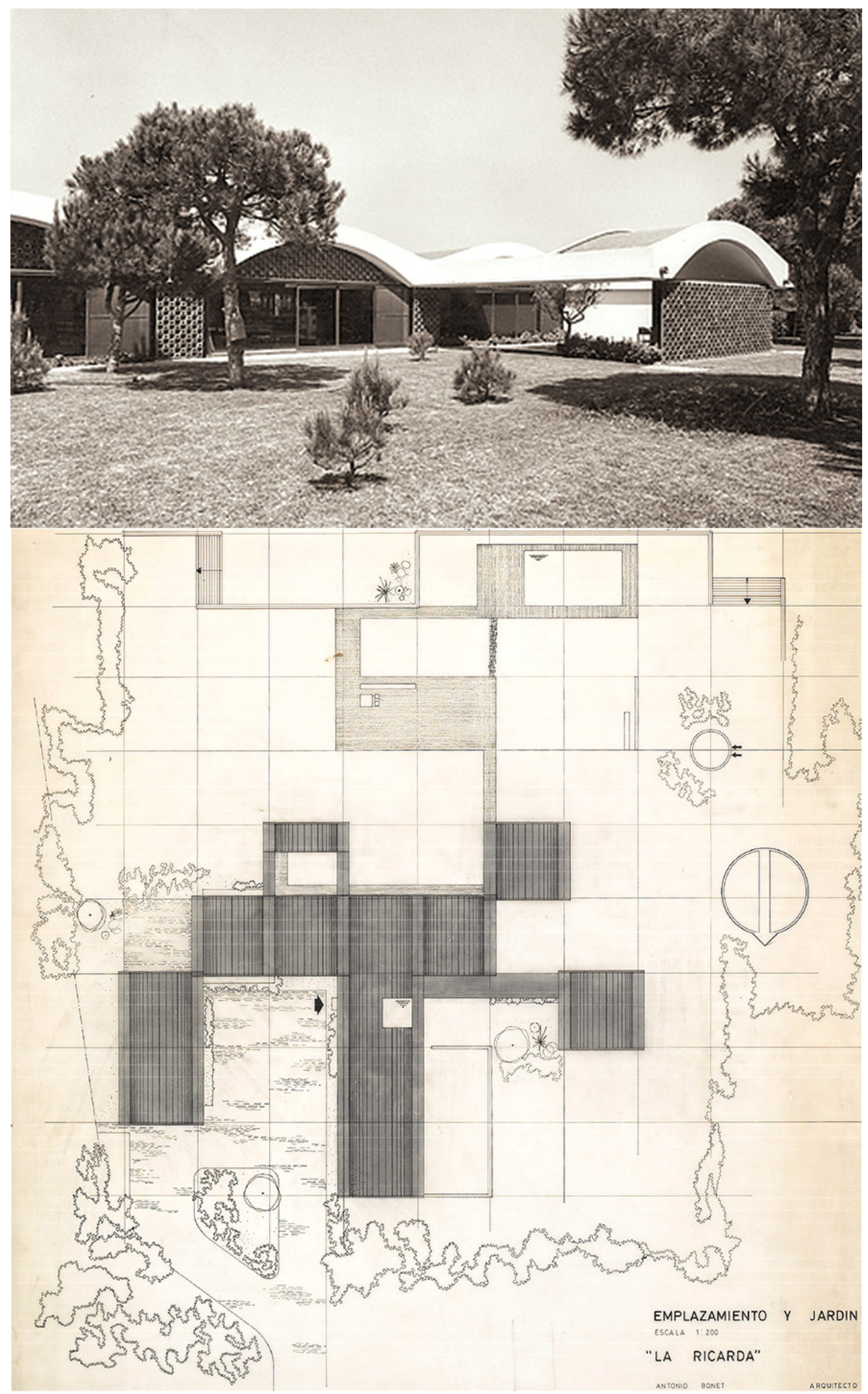

Figura 4. Casa La Ricarda. Fuente: AHC.

que caracteriza a la bóveda corrida (La Ricarda). El carácter de introspección visual de la casa se manifiesta también en el exterior, con la presencia de tapias que forman patios retranqueados alineados según el orden dictado por la trama. Una vez más, el módulo intermedio contiene la canal de recogida de pluviales con gárgolas que se expresan con rotundidad en las fachadas. Las cubiertas, revestidas de cerámica esmaltada tipo La Bisbal (34) se agrupan entre sí y se alternan con módulos de cubierta plana (en el garaje o en el recibidor). La ventilación de la cubierta se produce a través de cuatro orificios practicados en el dado que remata superiormente cada pirámide. El aire circula libremente, se produce una 

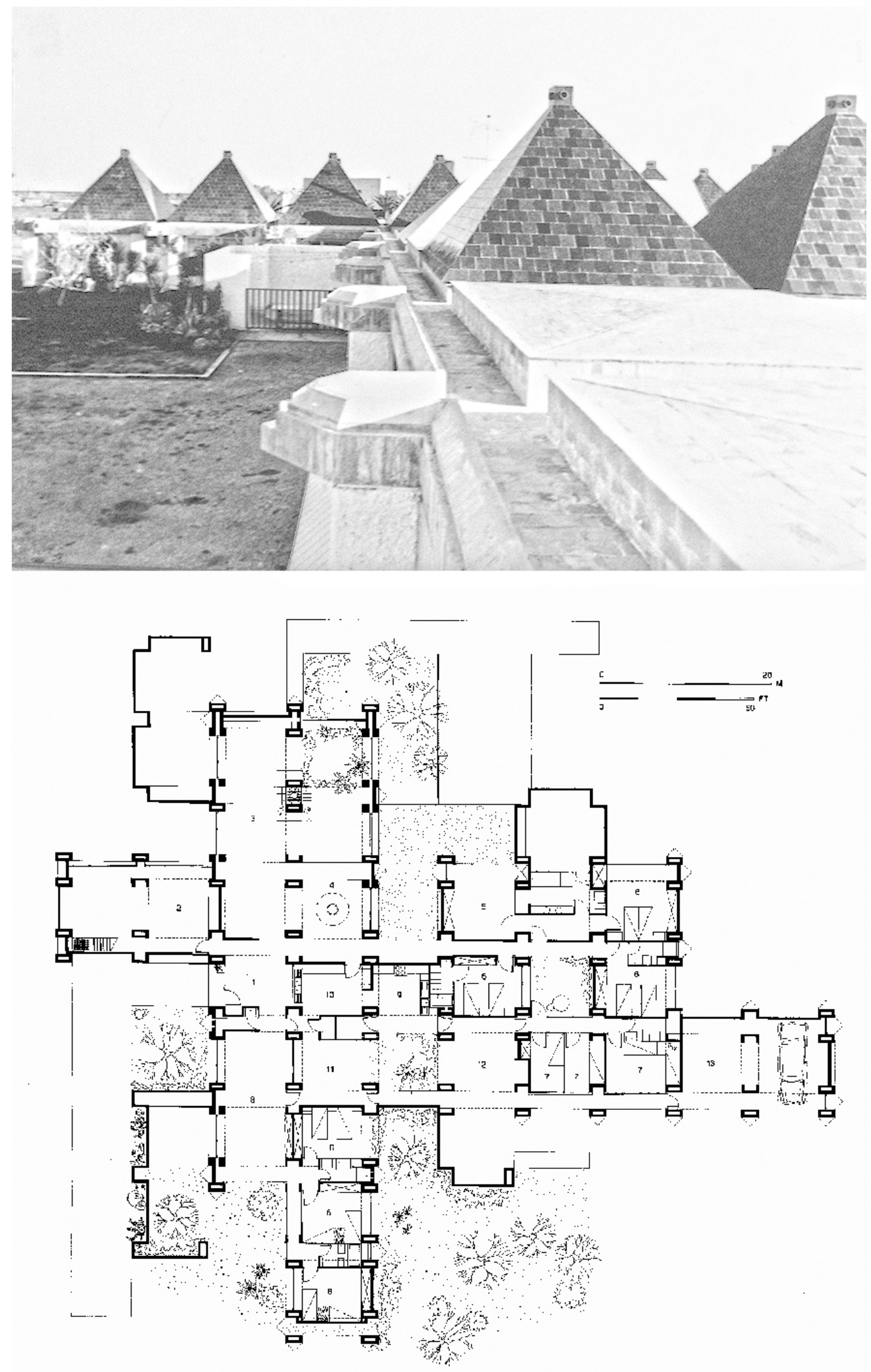

Figura 5. Casa Rubio. Fuente: AHC.

succión en sentido ascendente provocada por 'efecto Venturi'. Como veremos, el sistema se perfecciona en la escuela del poblado Hifrensa con una pirámide rebajada inferior soportante, de hormigón armado, aumentando considerablemente el volumen de la cavidad ventilada. En la Casa Rubio, Bonet propone una novedad respecto a experiencias anteriores, utiliza 'columnas huecas' formadas por cajones de obra, de 1.00xo,50m. Éstas columnas delimitan unas bandas a baja altura: 2,10 m, configurando espacios de gran flexibilidad de uso como se observa en la planta de la casa. Sirven para ubicar el equipamiento doméstico, chimeneas, pasos, aberturas, o simplemente delimitan o secuencian las áreas. Así, 
el sistema propuesto lleva implícito la distribución de la casa. Éste es un recurso, ya ensayado, también por Kahn en la casa Adler, Philadelphia, USA (1954-55).

\section{ESCUELA DEL POBLADO HIFRENSA, 1967-75}

La escuela del poblado Hifrensa (Fig. 6) y los ejemplos precedentes son obras de programa distinto pero comparten 'código genético'. La estrategia compositiva consiste en determinar una estructura modular con un elemento geométrico simple como es la pirámide (escuela/Rubio) y la bóveda rebajada (La Ricarda/Berlingieri), capaces de dotar al patrón de cualidades espaciales, lumínicas, acústicas o de ventilación. La definición del ritmo estructural $\mathrm{AB}-\mathrm{AB}-\mathrm{AB}$... parte de los ejes $\mathrm{N}-\mathrm{S}$ que se desdoblan creando un módulo intermedio, «A» y bóvedas o pirámides, «B». El módulo intermedio, «A», contiene la canal de recogida de agua de lluvia. Resuelve visualmente la transición entre pirámides o bóvedas, además se configura como un sistema para ordenar áreas y atribuir funciones. En la casa La Ricarda, se ubica el aseo, la escalera del sótano, la chimenea, la galería o el almacén del vestíbulo. En la escuela, se accede al aula, se define el ámbito del profesor, se ubica el equipamiento de las aulas formado por estanterías, armarios, lavamanos y fuentes. El módulo «B», forma la cubierta, ya sea bóveda o pirámide. En el interior cualifica las áreas con un sistema distribuidor consistente en la transición de funciones por transición de alturas. La defi- nición del patrón, permite resolver de un modo sistemático la división de cerramientos exteriores, despiece de pavimentos, revestimientos y modulación de aberturas.

\section{VIVIENDAS Y BUNGALÓS (BORDAS), 1968}

En 1968, Bonet propone un sistema modular para resolver un programa de bungalós (Bordas) y viviendas unifamiliares de veraneo en la urbanización Aigua Gelida proyectada por él mismo (35). El esquema reproduce a grandes rasgos, el esquema ya utilizado por Bonet en el ala de habitaciones de la casa Berlingieri. Mientras que la casa Berlingieri descansa sobre la plataforma que forma una duna, en esta ocasión, el autor, para resolver la privacidad de las estancias, recurre a elementos arquetípicos de la arquitectura vernácula como son patios y plataformas entendidas como abstracción del bancal agrícola catalán.

\section{FINAL DE ETAPA. CASA BALAÑ̃̀, 1974}

En 1974, Bonet ensaya ahora con un patrón esférico en otra vivienda unifamiliar de gran superficie, la casa Balañà (Fig. 7). Bonet, considera esta casa como uno de los logros más importantes de su obra (36). Podemos reconocer los mismos elementos, con un tamaño de módulo ajustado a 7.oom. Aquí, la figura es un casquete semiesférico que también provoca una sensación de recogimiento como la pirámi-
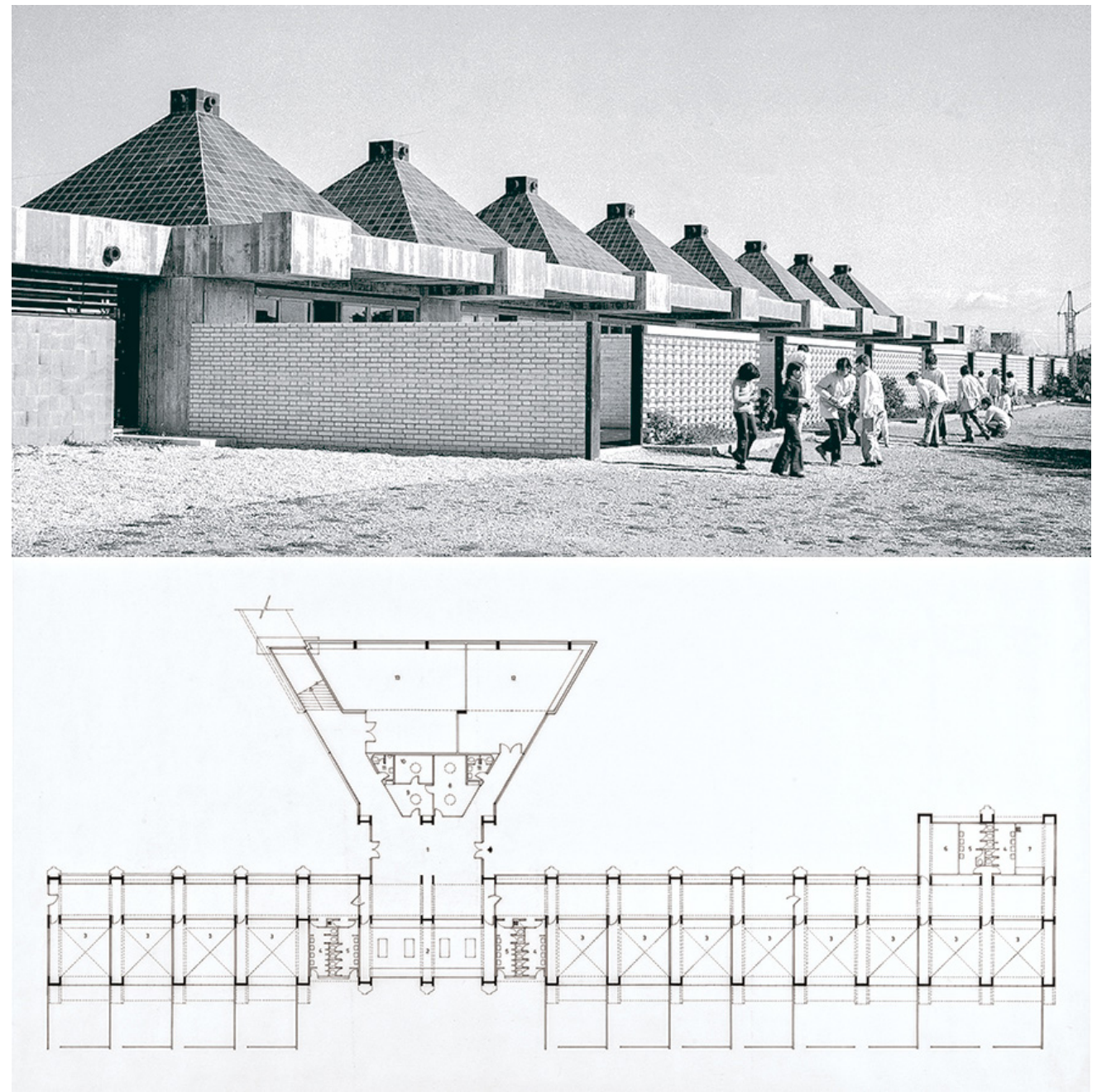

Figura 6. Escuela del poblado Hifrensa. Fuente: AHC. 


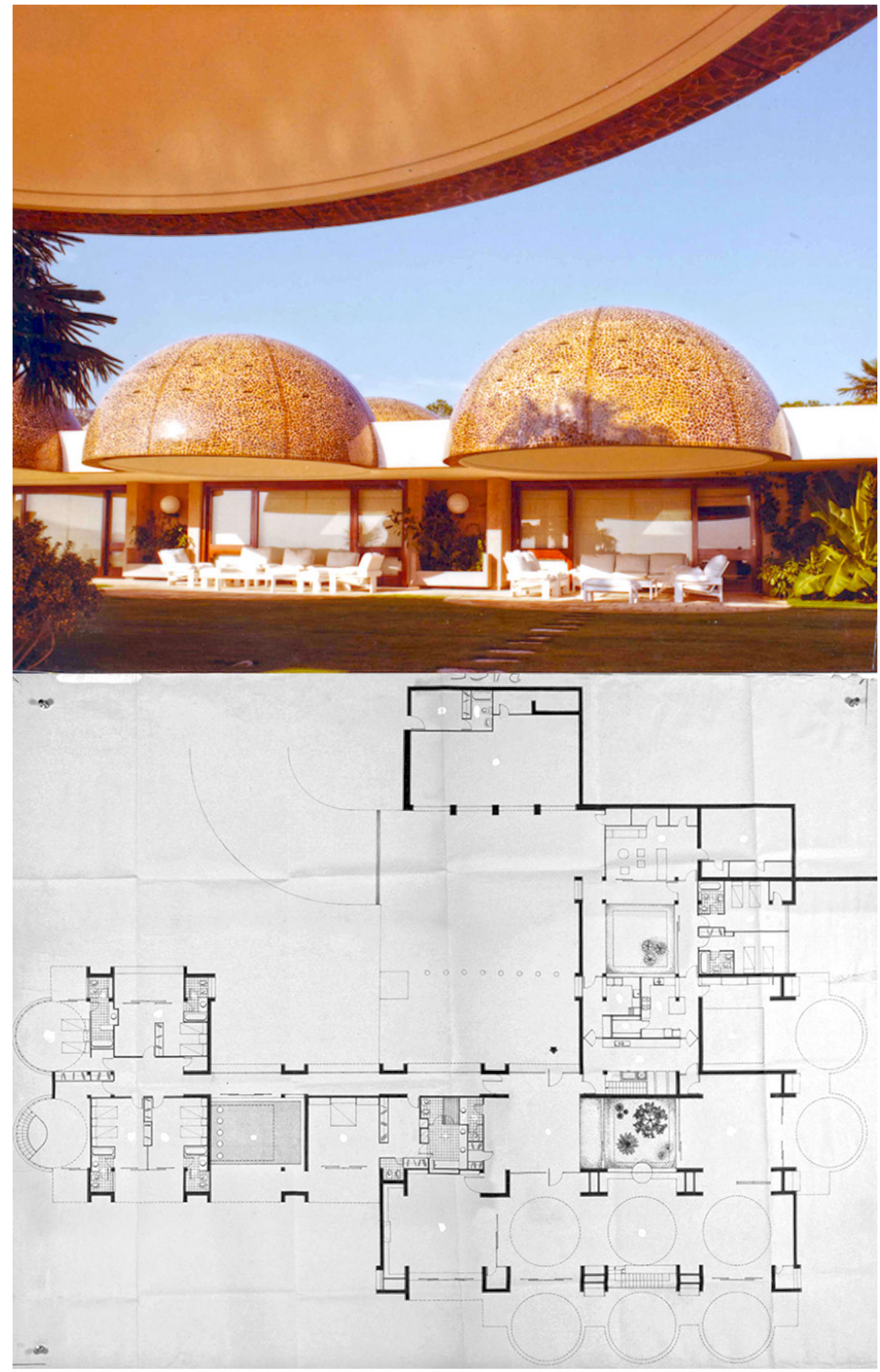

Figura 7. Casa Balañà. Fuente: AHC.

de. Una vez más, el módulo intermedio coincide con la canal de recogida de pluviales que se expresa en las fachadas con enormes gárgolas. El módulo se construye según una malla ortogonal definida por dobles pilares de hormigón armado de $30 \mathrm{~cm}$ de espesor, orientados en sentido NE-SO y SE-NO. Dichos pilares adoptan distintas formas en planta, «U» $\mathrm{y}$ «H» en general y ocasionalmente en forma de «L». Cuando se pretende provocar un giro en la distribución, estos dobles pilares, de $2.00 \mathrm{~m}$ de anchura, se utilizan para alojar el equipamiento doméstico, armarios, estanterías, aseos o jardineras. Las bandas entre pilares se utilizan para situar las escaleras que conectan con el nivel inferior de la vivienda. La cubierta se construye con una cámara ventilada entre la hoja inferior soportante, de hormigón armado, formada por un casquete 
esférico rebajado y la hoja superior formada por un tablero cerámico revestido con piezas de cerámica rota tipo La Bisbal utilizando la técnica del trencadís que se adapta mejor a superficies curvas tal y como pudo observar el autor en las cubiertas onduladas de Gaudí. Debe apuntarse que el casquete esférico no dispone de iluminación y la ventilación no es tan sofisticada como en la casa Rubio o en la escuela de Hifrensa. En cada cúpula se sitúan 24 orificios de ventilación, dispuestos en la banda central de las cúpulas.

La casa Balañà representa el punto final de la serie resuelta con módulos intermedios. Bonet construye espacios, no solo esculpiendo techos, también esculpe la luz revelada por la textura y por el grueso de muros y celosías. El contacto con el exterior, no se produce a través de la continuidad espacial propia del lenguaje de los primeros modernos (a través de una fina lámina). Funciona más como la corteza de un vegetal. Con el símil vegetal, podría definirse la serie, como una sucesión de cavidades en cubiertas y fachadas que superpuestas envuelven y dan cobijo al ser humano. En este sentido, podemos anticipar una primera conclusión: la arquitectura de Bonet no se centra únicamente en aspectos visuales, sino también atiende a sensaciones táctiles, acústicas, de confort térmico y lumínico que procura la elección de materiales por su aspecto y disposición constructiva. El carácter monolítico de la serie, opuesto al llamado 'plan libre' de los cinco puntos enunciados por Le Corbusier en 1927, y expresados en las villas parisinas de los años 20, no merma su flexibilidad de uso, bien al contrario, el sistema opuesto, 'plan paralysé', formado por muros y bóvedas, según los argumentos del profesor Xavier Monteys, genera espacios encadenados que pueden habitarse, aunque no importa como se usen, pudiendo cambiar de uso en el tiempo, sin que afecte a su apariencia (37). Valga de ejemplo el esquema piramidal, que puede valer tanto para una casa (Rubio), como para una escuela (Hifrensa). Los ejemplos precedentes se pueden englobar en una familia de edificios proyectados a partir de la revisión de la arquitectura de los primeros modernos promulgada por el propio Le Corbusier, en sus propuestas de inspiración vernácula de los años 50. También promulgada por los miembros del Team 10, quienes apostaron por cubriciones de extensión horizontal que Alison Smithson denominó en 1974 como Mat-buil$\operatorname{ding}(38)$.

\section{TRANSGRESIONES. SERIACIÓN CON BÓVEDAS TRONCOCÓNICAS}

A partir de los años 70, Bonet ensaya variaciones tipológicas prescindiendo del módulo intermedio. Propone una seriación de bóvedas adyacentes en forma de teja, ya sea con una disposición gualdrapeada de las mismas, en los bungalós Atamaría, La Manga del mar menor, Murcia (1972), ya sea con una disposición en abanico, en la Casa Raventós, Calella de Palafrugell, Girona (1973-74). En los bungalós Atamaría (Fig. 8), Bonet reproduce exactamente la disposición gualdrapeada (39) de tres bóvedas troncocónicas que definen las estancias principales de la Casa Cruylles, Aiguablava, Girona (1967-78) tal y como se puede observar en la maqueta realizada en el taller de historia de la ETSAB (Fig. 9). En esta ocasión, el módulo elemental, es más complejo y la unidad requiere de las relaciones espaciales que se establecen entre las tres bóvedas. La transgresión del tipo, viene dada por la influencia geográfica. En efecto, las formas caprichosas del accidente geográfico se pueden interpretar y transformar, a través del procedimiento abstracto del proyecto, en formas

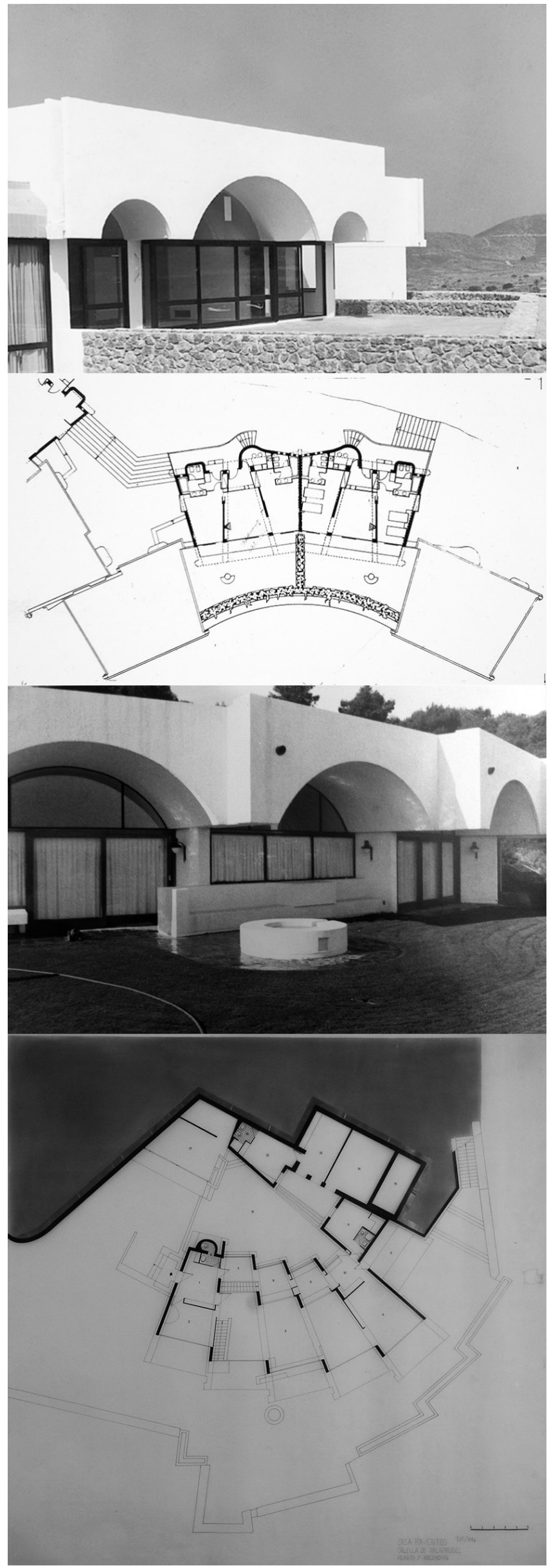

Figura 8. Bungalós Atamaría/casa Raventós. Fuente AHC. 

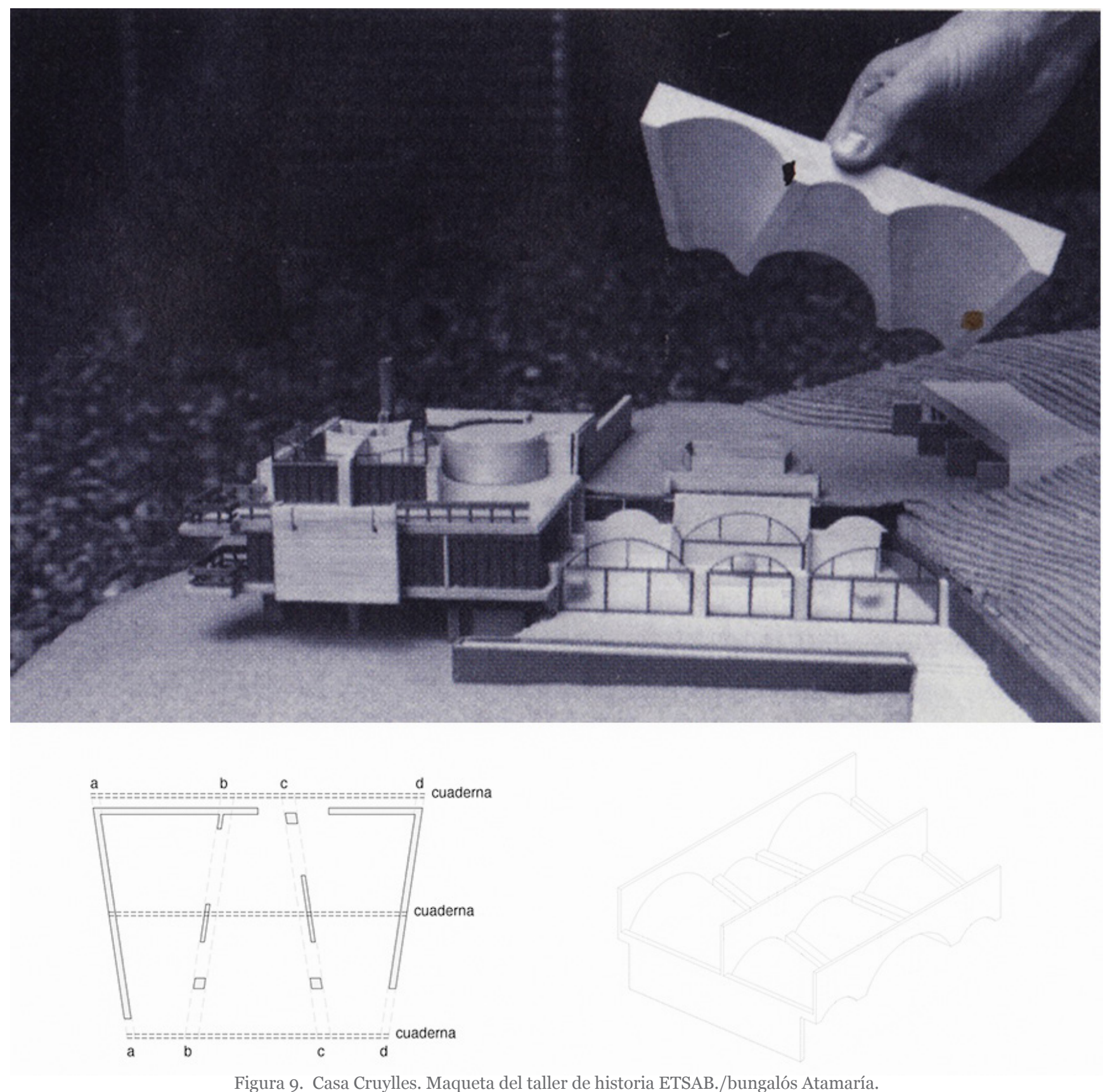

geométricas aptas para conformar espacios. La forma trapezoidal, semejante a la de una teja, de una vaguada de la casa Cruylles constituye un elemento figurativo que Bonet utiliza como estrategia proyectual:

Otro punto importante que contribuye a definir arquitectónicamente la casa es que la vaguada en donde se ha ubicado, y que tanto ha condicionado el posterior desarrollo del proyecto, tiene forma trapezoidal semejante a la de una teja. Esta forma es precisamente la que se adoptó como forma genérica; es decir, que todos los conceptos formales de la vivienda han sido consecuencia de ésta. El proyecto se elaboró. siguiendo un inicial criterio de modulación, eligiendo precisamente como módulo la forma trapezoidal antes descrita.(40)

En los bungalós Atamaría (Fig. 8), las bóvedas se sustentan sobre muros de ladrillo y jácenas de hormigón armado gene- rando nuevas relaciones espaciales en el interior de las mismas al no disponer de módulos intermedios. Mientras que en los ejemplos precedentes, la organización del programa se resolvía por alternancia entre módulos principales e intermedios en sentido transversal a las bóvedas, en este caso, la distribución y jerarquía de las estancias se modula progresivamente en sentido longitudinal, atendiendo a la progresiva disminución de anchura y altura que procura la forma troncocónica de la planta y del techo. El tamaño de las bóvedas (luz: 4.6o/1.80 m, longitud: $9.40 \mathrm{~m}$ ) y su disposición alterna, obliga a disponer de cuadernas o diafragmas ocultos en la cámara de aire (Fig. 9). En la memoria del proyecto de los bungalós Atamaría se describe con precisión el sistema constructivo empleado (41):

[sic]...La estructura vertical es una serie de muros de un pie de espesor y dos pilares de hormigón armado, que permite volar los apoyos de las bóvedas en la zona 
del porche principal. Sobre estos elementos se sitúan las vigas (véase planta). Las interiores $C D$, han de resistir la carga vertical y los empujes diferenciales entre bóvedas. Las exteriores $A B$, hacen de estribos, ya que van apoyados sobre muro, y además han de resistir los empujes horizontales totales; estos quedan sujetos en 3 puntos -centro y extremos-por medio de unas cuadernas o diafragmas que rigidizan las bóvedas y que absorben cualquier empuje. En cuanto a las bóvedas, son de rasilla, construida sobre cimbra y de 3 roscas. La primera al uso tradicional, tomada con yeso; la $2^{a}$ en mortero de cemento, sobre ésta se coloca un mallazo ligero, embebido en una capa de mortero de 2,5 cms. $Y$ por último, la $3^{a}$ rosca de rasilla. Todo ello se construye sobre cimbras. Las cuadernas se construyen sin encofrado de madera. Sobre la $2^{a}$ rosca de rasilla, y sobre el mallazo colocado, sin mortero, se encajan unos cercos abiertos, que sobresalen superiormente. Se rellena de mortero en la capa del mallazo y luego se construye la $3^{a}$ bóveda de rasilla, dejando abierta una faja del ancho de la cuaderna, esto es, de $15 \mathrm{cms}$. Sobre esta bóveda, se construyen los tabiquillos y dos tabicones, uno a cada lado de la cuaderna; todo ello naturalmente sin descimbrar las bóvedas.

En la casa Raventós (Fig. 8), otra vez, las formas caprichosas del accidente geográfico repercuten en la propuesta, mientras que el solar de la casa Cruylles se ubica en una vaguada, en la casa Raventós, el morro del acantilado sugiere formar una atalaya en abanico mirando al paisaje. La casa se resuelve con un sistema constructivo similar a los bungalós Atamaría, las bóvedas son algo mayores (luz: 4.75/1.80 m, longitud: $12.10 \mathrm{~m}$ ). Cada bóveda descansa en la parte inferior de vigas de canto que forman pórticos en abanico longitudinales a las bóvedas. Desconocemos la posición y el número de diafragmas o cuadernas, si hubieren.

\section{CONCLUSIONES}

1. A partir del análisis de la evolución del terrat Barcelonés, en el que podemos separar con claridad sus componentes constructivos, hemos tratado de verificar que la sofisticación constructiva en Bonet, no se produce tanto por la inclusión de materiales tecnológicamente avanzados, ya que se utilizan, en esencia, tecnologías ligadas a la tradición vernácula. También hemos podido verificar la íntima relación entre contenido constructivo y expresión formal para conseguir el «carácter de recogimiento humano» que persiguió Bonet. La sofisticación constructiva se produce a través de la definición de un módulo elemental con capacidad aditiva y combinatoria que satisface requerimientos programáticos distintos. Forma y tamaño de las cavidades ventiladas son indispensables en las cubiertas de la casa Rubio, ubicada en un lugar de condiciones climáticas severas, de la misma manera, también lo son en una escuela (Hifrensa). Por su parte, las bóvedas rebajadas de la casa La Ricarda se extienden horizontalmente en dos direcciones fusionándose con el pinar existente mientras que los bungalós Atamaría y la Casa Raventós forman atalayas sobre el paisaje. El detalle es distinto pero el rol asignado a cada componente constructivo es el mismo.

2. En los ejemplos precedentes, hemos podido verificar la atención dispensada por Bonet, no solo a aspectos visuales, también a sensaciones táctiles, acústicas, de confort térmico y lumínico que procura la elección de materiales por su aspecto y disposición constructiva. El carácter monolítico de la serie, no merma su flexibilidad de uso, bien al contrario, el sistema analizado genera espacios encadenados que pueden habitarse, aunque no importa como se usen, ya que la distribución va implícita en el diseño del patrón, pudiendo cam-biar de uso en el tiempo, sin que afecte a su apariencia.

\section{REFERENCIAS}

(1) Bonet, A. (1999). Nuevas precisiones sobre arquitectura y urbanismo, 1949. En Álvarez, F. y Roig, J., Antonio Bonet Castellana, (pp. 213, 221). Barcelona: Santa \& Cole.

(2) Ródenas, JF y Domingo, JR. (2015). Antonio Bonet y Josep Puig Torné. Series triangulares en Cap de Salou. RA Revista de arquitectura, (17): 57-64, doi: 10.15581/014.17.57-64.

(3) Ródenas, JF. (2015). Antonio Bonet. Espacios de transición entre vivienda y ciudad. RITA, (3): 54-73.

(4) Katzenstein, E., Natanson, G. y Schvartzman, H. (1985). Antonio Bonet. Arquitectura y Urbanismo en el Río de la Plata y España, p. 70, Buenos Aires: Espacio Editora.

(5) García, J., González, M. y Losada, J.C. (2012). Arquitectura y construcción tabicada en torno a Eduardo Sacriste. Informes de la Construcción, 64 (525): 35-50, doi: http://dx.doi.org/10.3989/ic.09.065

(6) Marín, AM. y Trallero, A. (2005, 27-29 de enero). El nacimiento de la cerámica armada. En Actas del Cuarto Congreso Nacional de Historia de la Construcción. Cádiz: ed. S. Huerta, Madrid: I. Juan de Herrera, SEdHC, Arquitectos de Cádiz.

(7) Marín, AM. (2007, 7-9 de junio). Cáscaras autoportantes de directriz catenaria sin tímpanos en cerámica armada. En Actas del Quinto Congreso Nacional de Historia de la Construcción. Burgos: ed: S. Huerta, Madrid: I. Juan de Herrera, SEdHC, CICCP, CEHOPU.

(8) Rodríguez, A. y Hernando, R. (2007). La bóveda tabicada y el movimiento moderno español. En Actas del V Congreso de Historia de la Construcción. (pp. 763-774)

(9) Montaner, A.A. (2014). Antonio Bonet Castellana, Le Corbusier y la bóveda catalana: forma y orden. DEARQ, (14): 122135.

(10) Gulli, R. (1999). La huella de la construcción tabicada en la arquitectura de Le Corbusier. En Las bóvedas de Guastavino en América. (p.77). Madrid: Instituto Juan de Herrera.

(11) Tomlow, J. (1999). La bóveda tabicada y el nacimiento de la cerámica armada. En Las bóvedas de Guastavino en América. Madrid: Instituto Juan de Herrera. p. 243.

(12) Entrevista a Antonio Bonet: Yo?...? Yo arquitecto (sin fecha). Fons Bonet: Archivo histórico COAC.

(13) Álvarez, F., et al. (1996). Antoni Bonet Castellana: 1913-1989, Barcelona: COAC. 
(14) Katzenstein, E., Natanson, G. y Schvartzman, H. (1985). Antonio Bonet. Arquitectura y Urbanismo en el Río de la Plata y España. Buenos Aires: Espacio Editora.

(15) Gulli, R. (1999). La huella de la construcción tabicada en la arquitectura de Le Corbusier. En Las bóvedas de Guastavino en América. (p. 77). Madrid: Instituto Juan de Herrera.

(16) Adell, J.M. y García, A. (2005). Gaudí y las bóvedas de las escuelas de la Sagrada Familia, Informes de la Construcción, 57 (496): 31-46.

(17) Gulli, R. (1999). La huella de la construcción tabicada en la arquitectura de Le Corbusier. En Las bóvedas de Guastavino en América. (p.77). Madrid: Instituto Juan de Herrera.

(18) Maniaque, C. (2009). Le Corbusier and the Maisons Jaoul. New York: Princeton Architectural Press.

(19) AA.VV. (1935). AC Documentos de actividad contemporánea, (19): 33-44.

(20) AA.VV. (1935). AC Documentos de actividad contemporánea, (18): 31-33.

(21) Rovira, JM. (2005). SERT 1928-1979 medio siglo de arquitectura. Obra completa, p. 83-85, Barcelona: Fundació Joan Miró.

(22) Bonet, A. y Zalba, H. (1945). Instituto de Aeronáutica de la Facultad de Ciencias Fisicomatemáticas de la UNLP: Anteproyecto para el edificio definitivo del Instituto». Revista de Arquitectura (289): 6-19.

(23) Graus, R. (2005) La cubierta plana, un paseo por su historia. p. 16-17, Barcelona: Texsa, Universitat Politècnica de Catalunya.

(24) Benavent, P. (1948). Como debo construir, Manual práctico de construcción de edificios, Barcelona: Ed. Bosch $3^{\mathrm{a}}$ ed.

(25) Paricio, A. (1998). La cámara ventilada como recurso constructivo durante el siglo XIX. En II Congreso nacional de historia de la construcción, p. 376, A Coruña: Universidade da Coruña.

(26) Paricio, A. (1996, 19-21 de septiembre). La innovación tecnológica de las cubiertas planas del GATCPAC. En Actas del primer congreso nacional de Historia de la Construcción (Vol. 19), p. 420-421, Madrid: eds. A. de las Casas, S. Huerta, E. Rabasa, Madrid: I. Juan de Herrera, CEHOPU.

(27) Marín, AM. y Trallero, A. (2005, 27-29 de enero). El nacimiento de la cerámica armada. En Actas del Cuarto Congreso Nacional de Historia de la Construcción. Cádiz: ed. S. Huerta, Madrid: I. Juan de Herrera, SEdHC, Arquitectos de Cádiz.

(28) Marín, AM. (2007, 7-9 de junio). Cáscaras autoportantes de directriz catenaria sin tímpanos en cerámica armada. En Actas del Quinto Congreso Nacional de Historia de la Construcción. Burgos: ed: S. Huerta, Madrid: I. Juan de Herrera, SEdHC, CICCP, CEHOPU.

(29) Álvarez, F., Roig, J. y Pich Aguilera, F. (1996). La Ricarda, Barcelona: COAC.

(30) Álvarez, F. y Roig, J. (2005). Rehabilitación de La Ricarda de Antonio Bonet, Tectónica, (18): 62-81.

(31) Marín, AM. (2007, 7-9 de junio). Cáscaras autoportantes de directriz catenaria sin tímpanos en cerámica armada. En Actas del Quinto Congreso Nacional de Historia de la Construcción. Burgos: ed: S. Huerta, Madrid: I. Juan de Herrera, SEdHC, CICCP, CEHOPU.

(32) Álvarez, F. y Roig, J. (2005). Rehabilitación de La Ricarda de Antonio Bonet, Tectónica, (18): 62-81.

(33) Mc Carter, R. (2005). Louis I. Kahn, p. 104-109, London: Phaidon Press.

(34) Pla, E. y Ródenas, JF. (2005). Antonio Bonet: Poblat HIFRENSA_Settlement. Tarragona: COAC.

(35) Ródenas, JF. (2013, 27-28 de junio). Planeamiento urbanístico en la obra de Antonio Bonet. De Punta Ballena al poblado HIFRENSA, 1945-1975. En V seminario internacional de investigación en urbanismo, pp. 214-231, Barcelona/Buenos Aires: DUOT.

(36) Entrevista a Antonio Bonet: Yo?...? Yo arquitecto (sin fecha). Fons Bonet: Archivo histórico del COAC.

(37) Monteys, X. (2002). Le Plan Paralysé: revisando los cinco puntos. Massilia: Anuario de estudios lecorbusierianos, p. 141.

(38) Smithson, A. (september, 1974) How to recognize and read mat-building. Mainstream architecture as it has developed towards the mat-building, Architectural Design (vol 9): 573-590.

(39) Roig, J. (1996). Relaciones cruzadas. Reflexiones sobre la arquitectura doméstica de A. Bonet. En Álvarez, F., et al. Antoni Bonet Castellana: 1913-1989, p. 58-69, Barcelona: COAC.

(40) AA.VV. (1970). Casa Port d'Esclanya, Aigua Blava (Costa Brava) Antonio Bonet: Arquitecto. Cuadernos de Arquitectura, (75): 45-49.

(41) «Bungalows en La Manga». Fons Bonet: Archivo histórico COAC. 